\title{
COMPOSIÇÃO DE SUBSTRATOS E TAMANHO DE RECIPIENTES NA PRODUÇÃO E QUALIDADE DAS MUDAS DE MARACUJAZEIRO 'AMARELO'
}

\author{
Composition of substrates and volume of recipients in the production and quality \\ of yellow passion fruit seedlings
}

\author{
Elisângela Aparecida da Silva ${ }^{1}$, Wilson Itamar Maruyama ${ }^{2}$, Vander Mendonça ${ }^{3}$, \\ Maria Gabriela Spindola Francisco ${ }^{4}$, Diógenes Martins Bardiviesso ${ }^{2}$, Mauro da Silva Tosta ${ }^{3}$
}

\begin{abstract}
RESUMO
A produção de mudas de maracujazeiro 'amarelo' (Passiflora edulis Sims. f. flavicarpa Degener) de boa qualidade genética, fitossanitária e bem nutridas é de suma importância. A multiplicação rápida depende de alguns fatores preponderantes, relacionados com a produção de mudas, ligados especificamente aos substratos e recipientes. Este experimento foi realizado visando à avaliação da produção de mudas em diferentes substratos e dois tamanhos de recipientes, em viveiro de produção de mudas da Universidade Estadual de Mato Grosso do Sul (UEMS), Cassilândia/MS. Foram testados quatro substratos: solo puro, solo + esterco (2:1 v:v), Plantmaxâ e solo $+150 \mathrm{mg} \cdot \mathrm{dm}^{-3}$ de superfosfato simples e dois tamanhos de recipientes de polietileno preto: $14 \times 20 \mathrm{~cm}(1000 \mathrm{~mL})$ e $10 \times 20 \mathrm{~cm}(700 \mathrm{~mL})$. Utilizou-se o delineamento experimental em blocos casualizados, em esquema fatorial 4 (substratos) x 2 (tamanhos de recipientes), com 4 repetições e dez plantas por parcela. Avaliaram-se as características: índice de velocidade de emergência (IVE), altura da muda (cm), comprimento de raiz $(\mathrm{cm})$, diâmetro do colo $(\mathrm{mm})$, número de folhas/planta, índice de clorofila foliar (ICC), massa seca da parte aérea, massa seca da raiz e massa seca total. Os resultados para as variáveis analisadas indicaram que apenas para o número de folhas/planta houve diferença significativa para o tamanho de recipiente utilizado. O solo + esterco e o Plantmax ${ }^{\circledR}$ favoreceram todos os parâmetros de crescimento nos recipientes de $700 \mathrm{~mL}$. O solo puro não é recomendado para a produção de mudas de maracujazeiro 'amarelo' em ambos recipientes; pois favoreceu apenas o comprimento de raiz e massa seca da parte aérea.
\end{abstract}

Termos para indexação: Passiflora edulis, propagação, superfosfato simples.

\section{ABSTRACT}

The production of yellow passion fruit seedlings (Passiflora edulis Sims. f. flavicarpa Degener) with genetic and phytosanitary quality, well-nourished and precocious, is of great importance. Fast multiplication depends on some preponderant factors related to seedling production, substrate and recipient. The experiment was realized to evaluate the production of seedlings in different substrates and two bulks recipients, in a seedling nursery at the Universidade Estadual do Mato Grosso do Sul, city of Cassilândia. Four substrates were evaluated: pure soil, soil + manure (2:1), Plantmax ${ }^{\circledR}$ and soil $+150 \mathrm{mg} \cdot \mathrm{dm}^{-3}$ of simple super phosphate and two recipient sizes made of black polystyrene: $14 \times 20 \mathrm{~cm}(1000 \mathrm{~mL})$ and $10 \times 20 \mathrm{~cm}(700 \mathrm{~mL})$. We used a completely randomized experimental design in a 4 (substrates) x 2 (recipients volume) factorial outline, with four replications and ten seeds per plot. The characteristics evaluated were: index of emergency speed (IVE), seedlings height $(\mathrm{cm})$, root length $(\mathrm{cm})$, lap diameter $(\mathrm{mm})$, number of leaves/plant, chlorophyll index (ICC), shoot and root dry mass and total dry mass. The results for the analyzed variables indicated that only for the number of leaves/plant there was a significant difference depending on the size of the recipient. The soil + manure and Plantmax ${ }^{\hat{a}}$ improved all growth parameters in the recipients of $700 \mathrm{~mL}$. Pure soil is not recommended for yellow passion fruit seedlings in both recipients, because they improved only root length and shoot dry mass.

Index terms: Passiflora edulis, propagation, simple super phosphate.

(Recebido em 27 de agosto de 2008 e aprovado em 16 de julho de 2009)

\section{INTRODUÇÃO}

O maracujazeiro 'amarelo' (Passiflora edulis Sims. f. flavicarpa Degener)é uma frutífera com ampla adaptação no Brasil, sendo considerada uma cultura que emprega grande quantidade de mão-de-obra, caracterizando-a como uma atividade agrícola familiar.

Alguns trabalhos científicos comprovam que a utilização de mudas de baixa qualidade genética, fitossanitária e mal-nutridas compromete a produtividade e longevidade da cultura. Pesquisas têm sido realizadas para a cultura do maracujazeiro 'amarelo', as quais têm dado ênfase a diferentes formulações de substratos para produção de mudas (Peixoto, 1986; Bellé \& Kämpf, 1993), sempre com obtenção de bons resultados.

Para a produção de mudas, normalmente, os substratos são preparados pelos próprios produtores que utilizam diversos materiais puros ou em misturas, levando

\footnotetext{
1Universidade Federal de Lavras/UFLA - Departamento de Agricultura/DAG - Cx. P. 3037 - 37200-000 - Lavras, MG - easag@hotmail.com 2Universidade Estadual de Mato Grosso do Sul/UEMS - Cassilândia, MS

3Universidade Federal Rural do Semi-Árido/UFERSA - Mossoró, RN

${ }^{4}$ Engenheira Agrônoma - Cassilândia, MS
} 
em consideração, principalmente, a disponibilidade regional. Os melhores substratos para formação de mudas devem apresentar algumas características importantes, tais como: disponibilidade de aquisição e transporte, ausência de patógenos, riqueza em nutrientes essenciais, $\mathrm{pH}$ adequado, textura e estrutura (Silva et al., 2001). Segundo Souza (1983), os substratos devem ser escolhidos em função da sua disponibilidade e de suas características físicas.

Geralmente, substratos com baixos teores de nutrientes são utilizados, necessitando assim, de complementação com adubações de cobertura (Decarlos Neto et al., 2002).

Dentre os macronutrientes, o fósforo tem ganhado destaque nas pesquisas relacionadas com a produção de mudas de espécies frutíferas nos últimos anos. A ausência ou a deficiência deste nutriente no substrato faz com que o sistema radicular fique menos desenvolvido, principalmente as raízes secundárias, o que reduz a capacidade da muda em absorver água e demais nutrientes para o seu desenvolvimento. Uma das fontes de fósforo mais comumente utilizada é o superfosfato simples, que é um adubo sintético obtido de rochas minerais após tratamento com ácido sulfúrico.

Para a produção de porta-enxerto de limoeiro 'Cravo' (Citrus limonia $\mathrm{L}$. Osbeck), doses crescentes de $\mathrm{P}_{2} \mathrm{O}_{5}$ na forma de superfosfato simples proporcionaram acúmulo linear de massa seca no caule e nas raízes das plantas (Azevedo et al., 2008).

Na produção de mudas de tamarindo (Tamarindus indica L.), utilizando-se doses de superfosfato simples aplicadas ao substrato, Reis et al. (2008) concluíram que a utilização desse adubo proporcionou incremento na produção de mudas, sendo que as variáveis diâmetro do colo, comprimento da parte aérea e massa seca do sistema radicular apresentaram comportamento linear crescente em relação às doses utilizadas.

Além da qualidade física e química do substrato utilizado, o tipo de recipiente exerce influência significativa no desenvolvimento de mudas. Para a produção de mudas de plantas frutíferas, vários tipos e tamanhos de recipientes podem ser utilizados, sendo que os mais comuns são os sacos de polietileno preto (Ribeiro et al., 2005).

De acordo com Tessarioli Neto (1995), a semeadura em recipientes é a forma mais empregada na produção de mudas de maracujazeiro, pois apresenta como vantagem: maior precocidade, menor possibilidade de contaminação fitopatogênica, melhor controle ambiental, aproveitamento das sementes e da área de produção de mudas e menor "stress" no transplante. Essas vantagens citadas se manifestam durante a produção de mudas e, posteriormente, na fase de transplante para o campo de produção comercial (Verdial et al., 2000).

Os sacos de polietileno comportam um volume de substrato que permite a obtenção de mudas vigorosas e de qualidade adequada para o plantio (Ribeiro et al., 2005). Mas, por outro lado, conforme o seu tamanho, contribuem para o aumento da área requerida para o viveiro e a elevação do custo de produção, de transporte e plantio da muda (Melo, 1999).

A utilização de novos substratos e tamanhos de recipientes pode favorecer a maior sobrevivência das mudas no campo, como também propiciar maior precocidade na sua obtenção, diminuindo assim os custos de produção.

Neste trabalho, objetivou-se avaliar o efeito de quatro tipos de substratos e dois tamanhos de recipientes na produção de mudas de maracujazeiro 'amarelo' de boa qualidade, bem nutridas, com maiores perspectivas de sucesso no campo.

\section{MATERIAL E MÉTODOS}

$\mathrm{O}$ experimento foi instalado e conduzido em viveiro telado com sombrite ( $50 \%$ de luminosidade), com temperatura média interna de $27,5^{\circ} \mathrm{C}$, entre os meses de janeiro e março de 2007, na Universidade Estadual de Mato Grosso do Sul (UEMS), Unidade de Cassilândia/MS. O local possui latitude $19^{\circ} 05^{\prime} \mathrm{S}$, longitude $51^{\circ} 56^{\prime} \mathrm{W}$, altitude de $471 \mathrm{~m}$ e, de acordo com a classificação climática de Köppen, apresenta Clima Tropical Chuvoso (Aw) com verão chuvoso (precipitação média anual de $1500 \mathrm{~mm}$ ) e inverno seco (precipitação de inverno menor que $60 \mathrm{~mm}$ ), temperatura média anual de $32^{\circ} \mathrm{C}$.

$\mathrm{O}$ delineamento experimental utilizado foi em blocos casualizados, em esquema fatorial 4 (substratos) x 2 (tamanhos de recipientes), num total de 8 (oito) tratamentos, com 4 repetições e dez plantas por parcela, perfazendo um total de 320 plantas.

O primeiro fator foi constituído de quatro substratos, sendo: solo puro, solo + esterco bovino (2:1 v:v), Plantmax ${ }^{\circledR}$ e solo +150 mg.dm ${ }^{-3}$ de superfosfato simples. Para o segundo fator, utilizaram-se sacos de polietileno preto de dois tamanhos: $14 \times 20 \mathrm{~cm}(1000 \mathrm{~mL}) \mathrm{e}$ $10 \times 20 \mathrm{~cm}(700 \mathrm{~mL})$. O solo utilizado neste trabalho, tanto puro como nas misturas, foi retirado de barranco. A análise química (pH, CE e macronutrientes) dos substratos é apresentada na Tabela 1.

Para o substrato solo + P $\left(150 \mathrm{mg} \cdot \mathrm{dm}^{-3}\right)$ não se realizou a análise química, a qual deve ser observada para a amostra de solo puro, considerando a adição de superfosfato simples. 
Tabela 1 - Análise química de substratos utilizados em experimento de produção de mudas de maracujazeiro 'amarelo', segundo metodologia específica para substratos, adotada pelo Instituto Agronômico de Campinas (IAC). UEMS, Cassilândia-MS, 2007.

\begin{tabular}{|c|c|c|c|c|c|c|c|c|c|c|c|}
\hline Substratos & $\mathrm{pH}$ & $\begin{array}{c}\mathrm{CE} \\
\mathrm{dS} / \mathrm{m}\end{array}$ & $\mathrm{N}-\mathrm{NO}_{3}$ & $P$ & $\mathrm{Cl}$ & $\begin{array}{l}\mathrm{S} \\
\mathrm{mg} / \mathrm{L}\end{array}$ & $\mathrm{N}-\mathrm{NH}_{4}$ & $\mathrm{~K}$ & $\mathrm{Na}$ & $\mathrm{Ca}$ & $\mathrm{Mg}$ \\
\hline Solo & 5,6 & 0,1 & 2,8 & 0,0 & - & 0,2 & 1,8 & 5,4 & 0,9 & 0,2 & 1,0 \\
\hline Solo + esterco & 5,2 & 0,3 & 25,2 & 1,8 & - & 3,4 & 1,9 & 9,3 & 7,3 & 18,3 & 9,1 \\
\hline Plantmax ${ }^{\circledR}$ & 4,2 & 3,0 & 72 & 11 & 200 & 560 & 4,7 & 156 & 32 & 234 & 193 \\
\hline
\end{tabular}

*Método de extração: 1:2 (Holanda). Métodos de determinação: N-(amoniacal e nitrato): destilação; K, Ca, Mg, P, S: ICP-OES.

As sementes foram adquiridas em casa comercial na cidade de Jales/SP, sendo semeadas três sementes por recipiente (Seleção 144 FELTRIN - 96\% germinação). O plantio foi realizado em 06/01/2007, a germinação iniciou em 15/01/2007 e o desbaste foi realizado em 30/01/2007, deixando uma plântula mais vigorosa por recipiente.

Após a semeadura e início da emergência de plântulas, procedeu-se à avaliação do índice de velocidade de emergência (IVE), baseado em Maguirre (1962), registrando-se diariamente o número de plântulas emergidas, sendo consideradas como emergidas as plântulas que apresentavam os cotilédones totalmente livres e normais.

Foram avaliadas as características altura da muda (cm), diâmetro do colo (mm), comprimento de raiz $(\mathrm{cm})$, número de folhas/planta, índice de clorofila foliar (ICC), massa seca da parte aérea $(\mathrm{g})$, massa seca da raiz (g) e massa seca total $(\mathrm{g})$.

A determinação da altura da muda foi realizada com uma régua graduada em milímetro, medindo a distância entre o colo e o ápice da muda. O diâmetro do colo foi medido cinco centímetros acima do colo da muda. Para isso, utilizouse um paquímetro digital com a leitura dada em milímetro. Para a medição do comprimento de raiz, utilizou-se uma régua graduada em milímetro. O índice de clorofila foliar foi determinado diretamente por um clorofilômetro (Chlorophyll Content Meter, CCM-200,da companhia OptSciences ${ }^{\circledR}$ ), sendo considerada uma das folhas do último par de folhas completamente expandido de cada planta.

A massa seca da raiz e da parte aérea foi obtida após secagem dessas partes da muda em estufa de circulação forçada de ar a $65^{\circ} \mathrm{C}$, até atingirem peso constante, procedendo à pesagem em balança analítica eletrônica $(0,001 \mathrm{~g})$. Com a soma das duas medições (massa seca da raiz e massa seca da parte aérea), foi obtida a massa seca total.

A avaliação das plantas foi realizada em 23/03/2007 (67 dias após a emergência), quando as mudas apresentavam condições ideais de serem transplantadas para o campo, sendo consideradas para avaliação quatro plantas por parcela.
Os resultados foram submetidos à análise de variância, e as médias comparadas pelo Teste de Tukey a $5 \%$ de probabilidade utilizando-se o programa computacional Sistema para Análise de Variância - SISVAR (Ferreira, 2000).

\section{RESULTADOS E DISCUSSÃO}

Pela análise de variância (Tabela 2), verifica-se que ocorreu efeito significativo $(p<0,01)$ dos diferentes substratos para as variáveis analisadas, enquanto para o fator recipiente houve diferença significativa $(p<0,05)$ somente para a característica número de folhas/planta. A interação entre substratos e recipientes não apresentou efeito significativo, portanto, os fatores atuam de maneira independente sobre as variáveis analisadas, mesmo assim as interações tinham interesse e foram desdobradas.

Os resultados obtidos discordam de Ribeiro et al. (2005), os quais encontraram interação para a maioria das características analisadas, porém deve-se ressaltar que os autores realizaram o experimento similar a este utilizando tubetes plásticos $(14,5 \times 3,5 \mathrm{~cm})$.

Na Tabela 3, observa-se que para o índice de velocidade de emergência (IVE), não houve diferença significativa para os tamanhos de recipientes testados. No entanto, houve diferença para o fator substrato, onde os melhores resultados foram obtidos com o substrato Plantmax $^{\circledR}$, mas que não diferiu significativamente dos demais substratos quando se utilizou o recipiente de 700 $\mathrm{mL}$ e, sendo superior apenas ao substrato solo + esterco, não diferindo dos demais no recipiente de $1000 \mathrm{~mL}$.

Esse substrato provavelmente reúne características físicas adequadas para favorecer o IVE, como boa porcentagem de microporos, conferindo ao substrato uma capacidade de retenção de água satisfatória, dessa forma, influenciando positivamente o desenvolvimento do sistema radicular das mudas (Guerrini \& Trigueiro, 2004). 
Tabela 2 - Quadrados médios para índice de velocidade de emergência (IVE), índice de clorofila foliar (IC), diâmetro do colo (DC), altura da muda (H), comprimento de raiz (CR), número de folhas/planta (NF), massa seca da parte aérea (MSPA), massa seca da raiz (MSRa) e massa seca total (MST) em função de diferentes substratos e tamanhos de recipientes na produção de mudas de maracujazeiro 'amarelo'. UEMS, Cassilândia-MS, 2007.

\begin{tabular}{|c|c|c|c|c|c|c|c|c|c|c|}
\hline Fontes de Variação & GL & IVE & $\begin{array}{c}\mathrm{IC} \\
(\mathrm{ICC})\end{array}$ & $\begin{array}{c}\mathrm{DC} \\
(\mathrm{mm})\end{array}$ & $\begin{array}{c}\mathrm{H} \\
(\mathrm{cm})\end{array}$ & $\begin{array}{c}\mathrm{CR} \\
(\mathrm{cm})\end{array}$ & NF & $\begin{array}{c}\text { MSPA } \\
(\mathrm{g})\end{array}$ & $\begin{array}{c}\text { MSRa } \\
(\mathrm{g})\end{array}$ & $\begin{array}{c}\text { MST } \\
(\mathrm{g})\end{array}$ \\
\hline Substrato & 3 & $39,54 * *$ & $1022,33 * *$ & $9,85^{* *}$ & $6334,39 * *$ & $165,44 * *$ & $72,46^{* *}$ & $27,96 * *$ & $1,25 * *$ & $44,74 * *$ \\
\hline Recipiente & 1 & $0,03^{\mathrm{ns}}$ & $45,74^{\mathrm{ns}}$ & $0,52^{\mathrm{ns}}$ & $650,79^{\mathrm{ns}}$ & $8,62^{\mathrm{ns}}$ & $6,35^{*}$ & $1,70^{\mathrm{ns}}$ & $0,02^{\mathrm{ns}}$ & $2,88^{\mathrm{ns}}$ \\
\hline Substrato*Recipiente & 3 & $5,25^{\mathrm{ns}}$ & $70,10^{\mathrm{ns}}$ & $0,03^{\mathrm{ns}}$ & $217,66^{\mathrm{ns}}$ & $9,57^{\mathrm{ns}}$ & $1,86^{\mathrm{ns}}$ & $0,77^{\mathrm{ns}}$ & $0,05^{\mathrm{ns}}$ & $1,68^{\mathrm{ns}}$ \\
\hline Bloco & 3 & $11,96^{\mathrm{ns}}$ & $145,76^{\mathrm{ns}}$ & $0,34^{\mathrm{ns}}$ & $831,71^{\mathrm{ns}}$ & $12,18^{\mathrm{ns}}$ & $0,86^{\mathrm{ns}}$ & $1,21^{\mathrm{ns}}$ & $0,05^{\mathrm{ns}}$ & $1,40^{\mathrm{ns}}$ \\
\hline Resíduo & 21 & 38,44 & 614,75 & 5,18 & 3404,84 & 109,43 & 16,31 & 14,35 & 0,77 & 21,17 \\
\hline C.V. $(\%)$ & & 15,54 & 21,95 & 15,47 & 35,42 & 11,59 & 11,45 & 42,21 & 42,40 & 40,95 \\
\hline
\end{tabular}

ns - não significativo pelo teste de Tukey aos níveis de 1 e $5 \%$ de probabilidade. $* *$ - significativo pelo Teste de Tukey a $1 \%$ de probabilidade. * - significativo pelo Teste de Tukey a $5 \%$ de probabilidade.

Tabela 3 - Médias de índice de velocidade de emergência, altura da muda (cm) e comprimento de raiz ( $\mathrm{cm}$ ) de mudas de maracujazeiro 'amarelo', em função de diferentes substratos e tamanho de recipientes. UEMS, Cassilândia-MS, 2007.

\begin{tabular}{|c|c|c|c|c|}
\hline \multirow[t]{2}{*}{ Recipiente (mL) } & \multicolumn{4}{|c|}{ Índice de velocidade de emergência } \\
\hline & Solo puro & Solo + S. Simples & Solo + Esterco & Plantmax $^{\circledR}$ \\
\hline 700 & $8,47 \mathrm{aA}$ & $9,03 \mathrm{aA}$ & $7,59 \mathrm{aA}$ & $9,63 \mathrm{aA}$ \\
\hline 1.000 & $9,05 \mathrm{abA}$ & $8,93 \mathrm{abA}$ & $6,40 \mathrm{bA}$ & $10,56 \mathrm{aA}$ \\
\hline C.V. $(\%)$ & & & & 15,54 \\
\hline \multirow[t]{2}{*}{ Recipiente (mL) } & \multicolumn{4}{|c|}{ Altura da muda $(\mathrm{cm})$} \\
\hline & Solo puro & Solo + S. Simples & Solo + Esterco & Plantmax $^{\circledR}$ \\
\hline 700 & $18,51 \mathrm{bA}$ & $25,98 \mathrm{abA}$ & $49,75 \mathrm{aA}$ & $31,53 \mathrm{abA}$ \\
\hline 1.000 & 22,98 bA & $31,00 \mathrm{bA}$ & $67,26 \mathrm{aA}$ & $40,60 \mathrm{bA}$ \\
\hline C.V. $(\%)$ & & & & 35,42 \\
\hline \multirow[t]{2}{*}{ Recipiente (mL) } & \multicolumn{4}{|c|}{ Comprimento de raiz $(\mathrm{cm})$} \\
\hline & Solo puro & Solo + S. Simples & Solo + Esterco & $\operatorname{Plantmax}^{\circledR}$ \\
\hline 700 & $19,95 \mathrm{abA}$ & $17,24 \mathrm{bA}$ & $18,18 \mathrm{abA}$ & $22,36 \mathrm{aA}$ \\
\hline 1.000 & $18,42 \mathrm{bA}$ & $18,64 \mathrm{bA}$ & $18,96 \mathrm{bA}$ & $24,86 \mathrm{aA}$ \\
\hline C.V. $(\%)$ & & & & 11,59 \\
\hline
\end{tabular}

*Médias seguidas de mesma letra minúscula na linha e maiúscula na coluna não diferem entre si pelo teste Tukey a 5\% de probabilidade.

Oliveira et al. (1993) obtiveram os melhores resultados para produção de mudas de maracujazeiro 'amarelo' com o substrato Plantmax ${ }^{\circledR}$, que, além de apresentar uma alta porcentagem de germinação para as sementes, também favoreceu o desenvolvimento das mudas.

Em relação à altura da muda, as melhores médias podem ser observadas para solo + esterco que não diferiu significativamente dos substratos solo $+150 \mathrm{mg} \cdot \mathrm{dm}^{-3} \mathrm{de}$ superfosfato simples e Plantmax ${ }^{\circledR}$ para o recipiente de 700 mL (Tabela 3).
O esterco de curral como componente de mistura para a produção de mudas de mamoeiro do grupo 'Solo', proporcionou os melhores resultados para a altura das mudas, segundo Negreiros et al. (2005).

O comprimento de raiz das plantas apresentou o melhor resultado com o substrato Plantmax ${ }^{\circledR}$ no recipiente de $1000 \mathrm{~mL}$, provavelmente, por ser um produto fisicamente uniforme e estável, permitindo desenvolvimento equilibrado da raiz e da parte aérea das plantas, além de não apresentar fermentação como no caso do esterco bovino. Já, no 
recipiente de $700 \mathrm{~mL}$ as maiores médias para esta variável foram obtidas no substrato Plantmax ${ }^{\circledR}$, mas não diferindo dos substratos solo puro e solo + esterco (Tabela 3).

Segundo Gonçalves \& Poggiani (1996), a formação do sistema radicular e parte aérea estão associadas à boa capacidade de aeração, drenagem, retenção de água e disponibilidade balanceada nos substratos.

O índice de clorofila foliar (ICC) também não foi afetado pelo tamanho de recipiente utilizado (Tabela 4). Em relação aos substratos, os melhores resultados para esta variável foram solo + esterco (2:1 v:v) no recipiente de $700 \mathrm{~mL}$, com um índice médio de 31,85 ICC, não diferindo do solo $+150 \mathrm{mg} \cdot \mathrm{dm}^{-3}$ de superfosfato simples e do Plantmax ${ }^{\circledR}$, enquanto os piores resultados foram observados para o substrato solo puro. Nos recipientes de $1000 \mathrm{~mL}$ o solo + esterco apresentou o maior índice de clorofila foliar (35,78 ICC), apesar de não ter diferido dos resultados obtidos com o solo $+150 \mathrm{mg} \cdot \mathrm{dm}^{-3} \mathrm{de}$ superfosfato simples.

Oliveira et al. (1993) observaram que o substrato Plantmax $^{\circledR}$ propiciou mudas com coloração verde mais intensa, que é um indicativo de índice de clorofila maior, consequentemente com maior possibilidade de desenvolvimento. Nesse experimento, a presença de esterco e de superfosfato simples favoreceu esta variável proporcionando índice de clorofila superior.

Das variáveis analisadas, apenas o número de folhas/planta foi afetado pelo tamanho de recipiente (Tabela 4). O saco de polietileno de $700 \mathrm{~mL}$ apresentou os piores resultados com o substrato solo $+150 \mathrm{mg} \cdot \mathrm{dm}^{-3} \mathrm{de}$ superfosfato simples. Para os substratos, as melhores médias foram obtidas com solo + esterco e com Plantmax ${ }^{\circledR}$, nos dois tamanhos de recipientes avaliados. Mendonça et al. (2007) concluíram que para a produção de mudas de mamoeiro 'Formosa', a característica número de folhas/ planta apresentou os melhores resultados, 8,99 folhas, para o substrato que continha a maior proporção de matéria orgânica (40\%).

De acordo com Carvalho Filho et al. (2003), o substrato composto por solo + areia + esterco bovino (1:2:1 $\mathrm{v}: \mathrm{v}: \mathrm{v})$ foi o que apresentou o melhor resultado para a produção de mudas de jatobá, em relação ao número de folhas/planta, provavelmente, por apresentar o esterco como matéria orgânica em sua composição.

O diâmetro do colo também não apresentou diferença significativa em relação aos tamanhos de recipientes testados (Tabela 4). Porém, os diferentes substratos influenciaram esta variável, sendo observado maior diâmetro do colo das mudas de maracujazeiro 'amarelo', para os substratos solo + esterco e Plantmax ${ }^{\circledR}$.
Para a produção de mudas de mamoeiro do grupo 'Solo', Negreiros et al. (2005) obtiveram resultados semelhantes para esta característica. Entre os substratos testados, a mistura de esterco de curral + solo + areia + vermiculita (2:1:1:1 v:v:v:v) foi a que proporcionou o maior diâmetro do caule $(7,75 \mathrm{~mm})$. Assim, o esterco como matéria orgânica, deve ser utilizado para a obtenção de mudas com diâmetro do caule maior, o que favorecerá seu índice de pegamento no campo, tanto para maracujá quanto para o mamoeiro.

A seguir, na Tabela 5, estão apresentadas as médias da massa seca da parte aérea, massa seca da raiz e massa seca total. Para estas características não foi observada diferença significativa para os tamanhos de recipiente utilizados.

Analisando apenas o recipiente de $700 \mathrm{~mL}$ não houve diferença significativa entre os substratos utilizados, no entanto, para o saco de polietileno maior $(1000 \mathrm{~mL})$ o substrato solo + esterco e o Plantmax ${ }^{\circledR}$ apresentaram médias superiores (3,75 g e 2,50 g, respectivamente) aos tratamentos solo puro e solo com adição de fósforo (Tabela 5).

Os sacos de polietileno permitem a obtenção de mudas vigorosas e de qualidade adequadas para o plantio, por outro lado, contribuem para o aumento da área requerida de viveiro e a elevação do custo de produção, de transporte e plantio da muda (Melo, 1999).

Para a massa seca da raiz observa-se que nos recipientes de $1000 \mathrm{~mL}$ e, nos recipientes de $700 \mathrm{~mL}$ o Plantmax ${ }^{\circledR}$, o solo + esterco e o solo +150 mg.dm ${ }^{-3}$ de superfosfato simples apresentaram médias superiores. Já, nos recipientes de $1000 \mathrm{~mL}$, os substratos Plantmax ${ }^{\circledR} \mathrm{e}$ solo + esterco apresentaram os melhores resultados, com valores de massa seca da raiz de 0,72 g e 0,69 g, respectivamente (Tabela 5).

Para a variável massa seca total (g) das plantas, não houve diferença significativa entre os recipientes testados (Tabela 5). No entanto, para os substratos, como era de se esperar, as melhores médias para esta variável foram novamente obtidas com solo + esterco $(4,84 \mathrm{~g})$ e o substrato Plantmax $^{\circledR}(3,16$ g), para o recipiente de $1000 \mathrm{~mL}$. Já, para o recipiente de $700 \mathrm{~mL}$ não foi observada diferença significativa entre os substratos Plantmax ${ }^{\circledR}$ (2,59 g), solo + esterco (3,49 g) e solo + $150 \mathrm{mg} \cdot \mathrm{dm}^{-3}$ de superfosfato simples $(1,55 \mathrm{~g})$.

Assim, observa-se que para as características altura da muda, índice de clorofila foliar, número de folhas por planta, diâmetro do colo e massa seca total os melhores resultados foram obtidos utilizando-se o substrato que continha o esterco bovino, provavelmente isso se deve não apenas ao suprimento de nutrientes feito pela presença da matéria orgânica, mas também à melhoria de outros constituintes de fertilidade do solo e aeração, no fornecimento de água, entre outros. 
Tabela 4 - Médias de índice de clorofila foliar (ICC), número de folhas/planta e diâmetro do colo ( $\mathrm{mm}$ ) de mudas de maracujazeiro 'amarelo', em função de diferentes substratos e tamanho de recipientes. UEMS, Cassilândia-MS, 2007.

\begin{tabular}{|c|c|c|c|c|}
\hline \multirow[t]{2}{*}{ Recipiente (mL) } & \multicolumn{4}{|c|}{ Índice de clorofila foliar (ICC) } \\
\hline & Solo puro & Solo + S. Simples & Solo + Esterco & Plantmax $^{\circledR}$ \\
\hline 700 & 16,68 bA & $23,51 \mathrm{abA}$ & 31,85 aA & $21,78 \mathrm{abA}$ \\
\hline 1.000 & $22,18 \mathrm{bA}$ & $26,07 \mathrm{abA}$ & 35,78 aA & $19,37 \mathrm{bA}$ \\
\hline C.V. $(\%)$ & & & & 21,95 \\
\hline \multirow[t]{2}{*}{ Recipiente (mL) } & \multicolumn{4}{|c|}{ Número de folhas/planta } \\
\hline & Solo puro & Solo + S. Simples & Solo + Esterco & Plantmax $^{\circledR}$ \\
\hline 700 & $5,94 \mathrm{bA}$ & $5,75 \mathrm{bB}$ & $9,50 \mathrm{aA}$ & $7,81 \mathrm{aA}$ \\
\hline 1.000 & $6,18 \mathrm{cA}$ & $7,31 \mathrm{bcA}$ & $10,19 \mathrm{aA}$ & $8,88 \mathrm{abA}$ \\
\hline C.V. $(\%)$ & & & & 11,45 \\
\hline \multirow[t]{2}{*}{ Recipiente $(\mathrm{mL})$} & \multicolumn{4}{|c|}{ Diâmetro do colo (mm) } \\
\hline & Solo puro & Solo + S. Simples & Solo + Esterco & Plantmax $^{\circledR}$ \\
\hline 700 & $2,43 \mathrm{cA}$ & $2,64 \mathrm{bcA}$ & $3,83 \mathrm{aA}$ & $3,43 \mathrm{abA}$ \\
\hline 1.000 & $2,66 \mathrm{cA}$ & $3,00 \mathrm{bcA}$ & $4,02 \mathrm{aA}$ & $3,69 \mathrm{abA}$ \\
\hline C.V. $(\%)$ & & & & 15,47 \\
\hline
\end{tabular}

*Médias seguidas de mesma letra minúscula na linha e maiúscula na coluna não diferem entre si pelo teste Tukey a 5\% de probabilidade.

Tabela 5 - Médias de massa seca da parte aérea (g), massa seca da raiz (g) e massa seca total (g) de mudas de maracujazeiro 'amarelo', em função de diferentes substratos e tamanho de recipientes. UEMS, Cassilândia-MS, 2007.

\begin{tabular}{|c|c|c|c|c|}
\hline \multirow[t]{2}{*}{ Recipiente (mL) } & \multicolumn{4}{|c|}{ Massa seca da parte aérea $(\mathrm{g})$} \\
\hline & Solo puro & Solo + S. Simples & Solo + Esterco & Plantmax $^{\circledR}$ \\
\hline 700 & $1,00 \mathrm{aA}$ & $1,25 \mathrm{aA}$ & $2,00 \mathrm{aA}$ & $2,75 \mathrm{aA}$ \\
\hline 1.000 & $1,00 \mathrm{bA}$ & $1,5 \mathrm{bA}$ & $3,75 \mathrm{aA}$ & $2,50 \mathrm{abA}$ \\
\hline C.V. $(\%)$ & & & & 47,25 \\
\hline \multirow[t]{2}{*}{ Recipiente (mL) } & \multicolumn{4}{|c|}{ Massa seca da raiz $(\mathrm{g})$} \\
\hline & Solo puro & Solo + S. Simples & Solo + Esterco & Plantmax $^{\circledR}$ \\
\hline 700 & $0,22 \mathrm{bA}$ & $0,30 \mathrm{abA}$ & $0,52 \mathrm{abA}$ & $0,65 \mathrm{aA}$ \\
\hline 1.000 & $0,23 \mathrm{bA}$ & $0,28 \mathrm{bA}$ & $0,69 \mathrm{aA}$ & $0,72 \mathrm{aA}$ \\
\hline C.V. $(\%)$ & & & & 42,40 \\
\hline \multirow[t]{2}{*}{ Recipiente (mL) } & \multicolumn{4}{|c|}{ Massa seca total $(\mathrm{g})$} \\
\hline & Solo puro & Solo + S. Simples & Solo + Esterco & Plantmax $^{\circledR}$ \\
\hline 700 & $0,98 \mathrm{bA}$ & $1,55 \mathrm{abA}$ & $3,49 \mathrm{aA}$ & $2,59 \mathrm{abA}$ \\
\hline 1.000 & $1,20 \mathrm{bA}$ & $1,80 \mathrm{bA}$ & $4,84 \mathrm{aA}$ & $3,16 \mathrm{abA}$ \\
\hline C.V. $(\%)$ & & & & 40,91 \\
\hline
\end{tabular}

*Médias seguidas de mesma letra minúscula na linha e maiúscula na coluna não diferem entre si pelo teste Tukey a 5\% de probabilidade.

\section{CONCLUSÕES}

O solo + esterco e o Plantmax ${ }^{\circledR}$ favoreceram todos os parâmetros de crescimento nos recipientes de $700 \mathrm{~mL}$.
O solo puro não é recomendado para a produção de mudas de maracujazeiro 'amarelo' em ambos os recipientes, pois favoreceu apenas o comprimento de raiz e massa seca da parte aérea. 
O tamanho de recipiente não influenciou significativamente no desenvolvimento das plantas, exceto na variável número de folhas/planta. sendo esta favorecida pelo recipiente de $1000 \mathrm{~mL}$ quando utilizado o substrato solo $+150 \mathrm{mg} \cdot \mathrm{dm}^{-3}$ de superfosfato simples;

Não ocorreu interação significativa entre os fatores tamanho de recipiente e substrato utilizado.

\section{REFERÊNCIAS BIBLIOGRÁFICAS}

AZEVEDO, E.B. de; ALTOÉ, J.A.; OLIVEIRA, A.F.; TERRA, M.I. da C.; MARINHO, C.S. Fontes e doses de $\mathrm{P}$ sobre o crescimento e estado nutricional do limoeiro 'cravo' cultivado em recipientes. In: CONGRESSO BRASILEIRO DE FRUTICULTURA, 20., 2008, Vitória. Anais... Vitória: DCM/Incaper, 2008. CD-ROM.

BELLÉ, S.; KÄMPF, A.N. Produção de mudas de maracujá-amarelo em substratos à base de turfa. Pesquisa Agropecuária Brasileira, Brasília, v.28, n.3, p.385-390, 1993.

CARVALHO FILHO, J.L.S. de; ARRIGONI-BLANK, M. de F.; BLANK, A.F.; RANGEL, M.S.A. Produção de mudas de jatobá (Hymenaea courbaril L.) em diferentes ambientes, recipientes e composições de substratos. Cerne, Lavras, v.9, n.1, p.109-118, 2003.

DECARLOS NETO, A.; SIQUEIRA, D.L. de; PERREIRA, P.R.G.; ALVAREZ, V.H. Crescimento de porta-enxertos de citros em tubetes influenciados por doses de N. Revista Brasileira de Fruticultura, Jaboticabal, v.24, n.1, p.199203, 2002.

FERREIRA, D.F. Análise estatística por meio do SISVAR (Sistema para Análise de Variância) para Windows versão 4.0. In: REUNIÃO ANUAL DA REGIÃO BRASILEIRA DA SOCIEDADE INTERNACIONAL DE BIOMETRIA, 45., 2000, São Carlos. Anais... São Carlos: UFSCar, 2000. p.255-258.

GONÇALVES, J.L.M.; POGGIANI, F. Substrato para produção de mudas florestais. In: SOLO-SUELOCONGRESSO LATINO AMERICANO DE CIÊNCIA DO SOLO, 13., 1996, Águas de Lindóia. Resumos expandidos... Águas de Lindóia: SLCS/SBCS/ESALQ/ USP/CEA-ESALQ/USP/SBM, 1996. CD-ROM.

GUERRINI, I.A.; TRIGUEIRO, R.M. Atributos físicos e químicos de substratos compostos por biossólidos e casca de arroz carbonizada. Revista Brasileira de Ciência do Solo, Viçosa, v.28, n.6, p.1069-1076, 2004.

MELO, B. de. Estudos sobre produção de mudas de cafeeiro (Coffea arabica L.) em tubetes. 1999. 119f. Tese (Doutorado em Fitotecnia)-Universidade Federal de Lavras, Lavras, 1999.

MENDONÇA, V.; ABREU, N.A.A. de; SOUZA, H.A. de; FERREIRA, E.A.; RAMOS, J.D. Diferentes níveis de composto orgânico na formulação de substrato para a produção de mudas de mamoeiro 'Formosa'. Caatinga, Mossoró, v.20, n.1, p.49-53, jan./mar. 2007.

NEGREIROS, J.R. da S.; BRAGA, L.R.; ÁLVARES, V. de S.; BRUCKNER, C.H. Diferentes substratos na formação de mudas de mamoeiro do grupo solo. Revista Brasileira Agrociência, Pelotas, v.11, n.1, p.101-103, jan./mar. 2005.

OLIVEIRA, R.P. de; SCIVITTARO, W.B.; VASCONCELLOS, L.A.B.C. de. Avaliação de mudas de maracujazeiro em função do substrato e do tipo de bandeja. Scientia Agricola, Piracicaba, v.50, n.2, p.261-266, 1993.

PEIXOTO, J.R. Efeito da matéria orgânica, do superfosfato simples e do cloreto de potássio na formação de mudas de maracujazeiro azedo (Passiflora edulis f. flavicarpa DENEGER). 1986. 101f. Dissertação (Mestrado em Fitotecnia)-Universidade Federal de Lavras, Lavras, 1986.

REIS, L.L.; TOSTA, M. da S.; TOSTA, P. de A.F.; GÓES, G.B. de; MENDONÇA, V.; BARDIVIESSO, D.M.;

TOSTA, J. da S. Adubação fosfatada na produção de mudas de tamarindeiro. In: CONGRESSO BRASILEIRO DE FRUTICULTURA, 20., 2008, Vitória. Anais... Vitória: DCM/Incaper, 2008. CD-ROM.

RIBEIRO, M.C.C.; MORAIS, M.J.A. de; SOUSA, A.H. de; LINHARES, P.C.F.; BARROS JÚNIOR, A.P. Produção de mudas de maracujá-amarelo com diferentes substratos e recipientes. Caatinga, Mossoró, v.18, n.3, p.155-158, jul./set. 2005.

SILVA, R.P. da; PEIXOTO, J.R.; JUNQUEIRA, N.T.V. Influência de diversos substratos no desenvolvimento de mudas de maracujazeiro azedo (Passiflora edulis Sims f. flavicarpa DEG). Revista Brasileira de Fruticultura, Jaboticabal, v.23, n.2, p.377-381, 2001. 
SOUZA, M. Nutrição e adubação para produzir mudas frutíferas. Informe Agropecuário, Belo Horizonte, v.9, n.102, p.40-43, 1983.

TESSARIOLI NETO, J. Recipientes, embalagens e acondicionamentos de mudas de hortaliças. In: MINAMI, K. Produção de mudas de alta qualidade em horticultura. São Paulo: T.A. Queiroz, 1995. cap.4, p.5964.

VERDIAL, M.F.; LIMA, M.S.; TESSAIROLI NETO, J.; DIAS, C.T.S.; BARBANO, M.T. Métodos de formação de mudas de maracujazeiro amarelo. Scientia Agricola, Piracicaba, v.57, n.4, p.795-798, 2000. 